\title{
Changes in the management model of health care institutions in health resorts in the context of social and economic changes in the years 1989-2018 in Poland
}

\author{
Adam R Szromek* \\ Silesian University of Technology, Faculty of Organization and Management, Poland
}

\section{Introduction}

Health resort treatment carried out by Health Resorts Facilities in the health resort areas in Poland is a permanent element of the national health care system [1]. The task of these health care institutions is to implement the national health policy goals, and - as a result treatment provided in the health resorts are funded by state insurance institutions. However, the statistics prove that in the last decades only a part of stays in health resorts is funded from the budget of national social insurer (National Health Fund or Social Insurance Institution), while more and more often the stay is financed by the direct recipient of the health resort treatment from its own resources. It is a phenomenon observed from the moment the health resort activities were marketed in Poland, meaning from 1989.

\section{Health Resorts Facilities and their conditions}

Research on the changes in the model of health resort treatment organization carried out at Faculty of Organization and Management of Silesian University of Technology and funded by National Science Center in Poland ${ }^{1}$ prove, that these changes are:

- Economic (by marketing the health resort services [2],

- Social (due to the popularity of the healthy life style and aging society [3],

- Proprietary (by way of privatization of the health resorts facilities [4].

Even though the transformation that occurred in Poland at the turn of 20th and 21st century concerned many aspects of social and economic life, these three phenomena influenced the shape of the health resort market the most and initiated changes in the models of organization of health resort treatments.

The history of health resort treatment in Poland proves, that in the second half of 20th century, the predominant (and quite often the only one) goal of health resort facilities functioning was the social objective concerning the implementation of the state health promotion initiatives. It was possible, because the health resort services were fully financed by the state budget. The turn of the 20th and 21st century

1 The research is carried out by the team supervised by professor A.R. Szromek in the Institute of Economy and Informatics of the Faculty of Organization and Management of Silesian University of Technology in the years 2018-2020. The research project 'A business model for health resort enterprises' No. 2017/25/B/HS4/00301 is supervised and financed by the National Science Center in Poland. Its aim is to propose a new form of the organization of health resort treatments in Poland. resulted in the loss of financing coming from the central budget and triggered the necessity to look for funds by signing contracts with state health insurers. The changes both in the national health system introduced in 1999 as well as changes in the ownership structure of health resort enterprises (by way of their complete privatization in the years 2005-2016) made it necessary to change the way in which their activity is perceived. These facilities became, first of all profit-oriented entities and only later entities that want to implement social goals [2].

Apart from the changes mentioned above, concerning the economic situation, legal environment, ownership structure and used technologies, one must also note the changing social and cultural trends. It is mostly about the popularity of healthy life style. This idea brought about the change of the market offer, taking into account not only the traditional treatments covering balneology and physical medicine, but also modern recreational services (SPA\&Wellness). What is more, changes in European demographics, in particular low fertility rate in the Polish society ( 1.3 child per mother [5]) forecast a growing demand for health services, including health resort treatments.

Central Statistical Office data [6] concerning health resort treatment in Poland prove, that from 1995 the number of spas, and spa hospitals is constant, despite slight fluctuations. At the same time, the number of beds being at the disposal of health resort visitors increases. The popularity of health resort treatments also grows, as in 2016 an increase by $76 \%$ was noted as compared with 1995 . In 1995 , approximately 420 thousand people visited Polish health resorts, while in 2016 the number was 737 thousand visitors. Unfortunately, along with the growing number of visitors of Polish health resorts, the average duration of stay decreases. Despite the widely accepted 21-day period of health resort treatment, currently the duration of stay is 17 days. This is, still, a significant result.

The transformation on the Polish market of health resort treatment at the turn of centuries and growing popularity of healthy life style together with the aging of the Polish society result in the necessity to change the used business model or at least in the update of its components at health resorts facilities.

${ }^{\star}$ Correspondence to: Adam R Szromek, Silesian University of Technology, Faculty of Organization and Management, Poland. Tel: 4832277 7358; E-mail: aszromek@polsl.pl

Received: March 14, 2018; Accepted: March 26, 2018; Published: March 29, 2018 


\section{Changes in the health resort facilities management models}

Although the research carried out in health resort facilities is still ongoing, currently it is possible to indicate several key problems of the modern business models of these facilities. What is particularly noticeable are the weak points in communication with a potential visitor and in building a strong relation with the recipients of the health resort services. It concerns both the usage of outdated communication channels and underestimation of electronic media, as well as treatment of the patient, who does not pay directly for the treatment but is only a beneficiary.

From among the shortcomings of the elements of the current health resort business models one must pay attention to, among others, the lack of offer covering free time that the patient undergoing treatment has, lack of integration with the use of free time arrangement in spas and spa hospitals. Major weaknesses are also natural therapy programs based on traditional, yet outdated outpatient treatment methods as well as a lack of coordination of individual health resort treatment plans with the overall organization of the patient's stay at the health resort. This weakness results mainly from the fact that the level of patient satisfaction from the treatment is not taken into account due to the uneven balance between demand over supply of treatments funded by the insurers and the lack of direct contact with the health resort visitor and lack of interest in his or her needs.

In the proposed approach to the health resort treatment business model structure, we can see an attempt to answer the needs voiced by the health resort visitors and potential visitors. The key activities of health resorts must be supplemented with services enriching the health resort treatment, for example tourist service or free time arrangement. It is equally important to introduce methods of accommodation optimization (that lower the accommodation costs) and methods of therapeutic treatments implementation (which, in turn, should improve the patients' satisfaction).

It is also crucial to expand the proposal of value that the health resorts facilities are offering their direct recipients. It is not only about correctly rendered treatment with accommodation and catering. Immaterial values that go beyond the health effect also constitute a value for the health resort visitor. Quite often, the health resort visitor wants to make use of tourist attractions, looking for interesting experiences in the sphere of culture, entertainment and religion. Some market segments will expect yet different values, for example in the availability of health resort parks and walking routes and trails used for sport, recreational and tourist purposes. An important element expanding the health resort offer are services helping to improve one's weight (slimming treatment) and beauty (cosmetic medical treatments), as well as professional psychophysical therapies (anti-stress treatments).

At the level of organization, an important element is also the possibility of establishing a cooperation between health resort competitors (both indirect and direct one in the scope of complementary and substitutable products). They can strengthen their partnership in areas in which they do not have to compete with one another.

It is also worth analyzing re-segmentation of health resort services recipients market. Not only the manner in which the patient's stay is financed is important, but also the conscious selection of location and duration of stay, as well as the duration of the treatment. A key factor will also be the purpose of the visit, as well as the return to the same location and the experience in undergoing health resort treatments. The segmentation necessity will also result from the changes in the types of relations between the health resort enterprise and health resort visitor. Modern health resort businesses model should be targeted towards the market dependency of B2C (Business-to-Customer) type, creating especially value for the customer, instead of the currently used approach of B2B (Business-to-Business) or B2A (Business-toAdministration) type that refer to direct payers (insurers).

\section{Conclusions}

The transformation of health resort treatment organization model in Poland that has been taking place over the last two decades is progressing in the direction of marketing this area of national health system. Following that transformation, the elements deciding on the character of the medical treatments offered in the health resorts also are changing. The state control over the health resort treatment services being rendered grows weaker. The growing popularity of this form of treating with natural resources induces the managers of these facilities to introduce bold changes that meet the health resort visitors' expectations.

\section{Acknowledgments}

This paper was published as part of the research project 'A business model for health resort enterprises' No. 2017/25/B/HS4/00301, supervised and financed by the National Science Center in Poland and as part of statutory research ROZ 1:BK-231/ROZ1/2018 (13/010/ BK_18/0029) at the Silesian University of Technology, Faculty of Organization and Management.

\section{References}

1. Health Resort Treatment (2005) Health Resorts, Health Resort Protection Areas and Health Resort Communes Act of July 28 .

2. Kapczynski A, Szromek AR (2008) Hypotheses concerning the development of Polish spas in the years 1949-2006. Tourism Management 29: 1035-1037.

3. Szromek AR, Januszewska M, Romaniuk P (2012) Demographic Phenomena and Demand for Health Tourism Services Correlated in Poland. American Journal of Tourism Management 1: 10-20.

4. Szromek AR, Romaniuk P, Hadzik A (2016) The privatization of spa companies in Poland - An evaluation of policy assumptions and implementation. Health Policy 120: 362-368. [Crossref]

5. Data (2018) Fertility rate, total (births per woman) The World Bank, IBRD.

6. Statistics Poland (2018) Local Data Bank (for the years 1995-2018).

Copyright: @2018 Szromek AR. This is an open-access article distributed under the terms of the Creative Commons Attribution License, which permits unrestricted use, distribution, and reproduction in any medium, provided the original author and source are credited. 